\title{
Photosynthetic and yield responses of rice (Oryza sativa L.) to different water management strategies in subtropical China
}

\author{
X.H. WU,**, W. WANG ${ }^{*,+}$, X.L. XIE* , C.M. YIN ${ }^{*}$, and K.J. XIE ${ }^{* * *}$ \\ Key Laboratory of Agro-ecological Processes in Subtropical Region, Institute of Subtropical Agriculture, \\ Chinese Academy of Sciences, Changsha - 410125, Hunan, China* \\ Faculty of Life Science and Technology, Central South University of Forestry and Technology, \\ Changsha-410004, Hunan, China ${ }^{* *}$ \\ Hunan Agricultural Resources and Environmental Protection Management Station, Changsha - 410008, Hunan, China ${ }^{* * *}$
}

\begin{abstract}
An experiment was performed to study gas exchange and chlorophyll fluorescence responses of rice (Oryza sativa L.) to various regimes, such as flooding-midseason drying-flooding (FDF), flooding-midseason drying-saturation (FDS), and flooding-rain-fed (FR) regimes. Compared to FDF, FR resulted in an obvious decrease in net photosynthetic rate $\left(P_{\mathrm{N}}\right)$, due to the decrease in stomatal conductance and the increase in stomatal limitation. In contrast, FDS plants did not suffer stomatal limitation and had comparable $P_{\mathrm{N}}$ with FDF plants. For diurnal light-saturated electron transport rate and saturation irradiance, FDF performed the best, which was followed by FDS and FR successively. FR and FDS plants tended to suffer from midday depression. FDS reduced irrigated water by $17.2 \%$ compared to FDF for comparable yields. The results suggested that FDS can be an effective irrigation regime to save water.
\end{abstract}

Additional key words: rapid light curve; water productivity; water saving.

\section{Introduction}

Rice (Oryza sativa L.) production takes up about $11 \%$ of the global cultivated land (Khush 2005), and consumes about $34-43 \%$ of the global irrigation water (Bouman et al. 2007). Rice cultivation has shaped the cultures, diets, and economies in Asia, where $90 \%$ of rice is grown and consumed (Khush 2005). Rice is mostly cultivated in puddled fields with flooded water, accounting for approximately $50 \%$ of the irrigated area in Asia (Barker et al. 2004). Water deficit is a major abiotic stress factor limiting crop productivity worldwide, which more or less affects about $50 \%$ of the world rice production (Belter et al. 2004, Lal et al. 2012, Akram et al. 2013, Ambavaram et al. 2014, Zhou et al. 2017). With climate change and rapidly increasing demands for higher valued uses (industry, municipal use, and hydropower), water resource for agriculture sector is becoming increasingly scarce (Barker et al. 2004, Wei et al. 2010, Elliott et al. 2013, Yan et al. 2015). At present, the challenge is to produce more rice with less water in order to meet the increasing demand for rice due to growing population.

Water loss in rice cultivation is mainly caused by evaporation, seepage, percolation, and surface runoff (Bouman et al. 2007, Alberto et al. 2011, Thakur et al. 2014). To cut down the unproductive water outflows, researchers have developed a promising water-saving irrigation regime to keep soil saturated without waterlogging, which is called saturated soil culture. Some researchers found that saturated soil culture increased grain yield by 9-15\% compared to continuously flooded culture (Pan et al. 2009, He 2010, Escasinas and Zamora 2011, He et al. 2014). However, some researchers reported no yield increase or small yield reductions (Bouman and Tuong 2001, Tabbal et al. 2002, Zain et al. 2014). Those previous reports indicate that saturated soil culture has the potential to increase rice

Received 31 May 2017, accepted 29 November 2017, published as online-first 13 April 2018.

${ }^{+}$Corresponding author; fax: +86-731-84612685; e-mail: wangw@isa.ac.cn

Abbreviations: $C_{\mathrm{a}}-$ ambient $\mathrm{CO}_{2}$ concentration; $\mathrm{Chl}-$ chlorophyll; $C_{\mathrm{i}}-$ intercellular $\mathrm{CO}_{2}$ concentration; $E-$ transpiration rate; $\mathrm{E}_{\mathrm{m}}-$ saturation irradiance; ETR - electron transport rate; ETR $\max$ - light-saturated ETR; FDF - flooding - midseason drying - flooding water regime; FDS - flooding - midseason drying - saturating water regime; FR - flooding - rain-fed water regime; $F_{m}{ }^{\prime}$ - maximal fluorescence yield of the light-adapted state; $\mathrm{F}_{\mathrm{t}}$ - instantaneous fluorescence; $g_{\mathrm{s}}$ - stomatal conductance; $\mathrm{L}_{\mathrm{s}}-$ stomatal limitation value; $P_{\mathrm{N}}-$ net photosynthetic rate; RLC - rapid light curve; WP - water productivity; $\Phi_{\mathrm{PSII}}-$ effective quantum yield of PSII photochemistry. Acknowledgements: This work was supported by the National Natural Science Foundation of China (grant numbers: 41401292 and 41503081) and the International Science \& Technology Cooperation Program of China (grant number: 2015DFA90450). 
yield, or at least, it could obtain the comparable yield when compared to continuous flooding culture.

China has the world's second largest planting area with the highest rice production, accounting for $18.8 \%$ of the world rice area and $28.1 \%$ of the global rice production (FAO 2014). The south of China is the major riceproducing region, where midseason drying (FDF) is prevailing. The most representative saturated soil culture is flooding-midseason drying-saturation (FDS) cycle. After midseason drying, irrigation is applied to make the soil saturated without ponded water. Traditionally, rice is also grown under rain-fed conditions (FR), mainly due to the lack of irrigation. Rain-fed lowland rice is grown in 54 million out of 163 million ha of world rice area (Bouman et al. 2007, FAO 2014). Photosynthesis is the basis of crop growth and yield formation (Ambavaram et al. 2014). However, there is little information on the physiological basis of rice photosynthesis, which leads to

\section{Materials and methods}

Experimental site: The experiment was carried out at Taoyuan Station of Agro-ecology Research $\left(111^{\circ} 27^{\prime} \mathrm{E}\right.$, $28^{\circ} 55^{\prime} \mathrm{N}$ ) from June to October in 2011. The region is characterized by subtropical humid monsoon climate, with an average annual air temperature of $16.5^{\circ} \mathrm{C}$, precipitation of $1,448 \mathrm{~mm}$, sunshine of $1,513 \mathrm{~h}$, and frost-free period of $283 \mathrm{~d}$. The soil is developed from Quaternary red clay. Characteristics of the soil were as follows: soil organic carbon (SOC) $17.1 \mathrm{~g} \mathrm{~kg}^{-1}$, total nitrogen of $1.79 \mathrm{~g}(\mathrm{~N}) \mathrm{kg}^{-1}$, total phosphorus of $0.58 \mathrm{~g}(\mathrm{P}) \mathrm{kg}^{-1}$, total potassium of $12.1 \mathrm{~g}(\mathrm{~K}) \mathrm{kg}^{-1}$. Precipitation and air temperature were measured at a meteorological station nearby the experiment field, which was within $100 \mathrm{~m}$. Specific precipitation and air temperature are shown in Fig. 1, with an average annual air temperature of $24.8^{\circ} \mathrm{C}$ and precipitation of $234 \mathrm{~mm}$ from rice transplanting to harvest.

Experimental design: The water regimes were: floodingmidseason drying-flooding (FDF), flooding-midseason drying-saturating (FDS), and flooding-rain-fed (FR). Each treatment had three replicates. In all the treatments, fields were flooded with about $10-\mathrm{cm}$ water layer for land preparation and seedling transplanting. Midseason drying was carried out at the end of the tillering stage, and it lasted for about one week. In the FDF plots, 2-10-cm water layer was kept after midseason drying. In the FDS plots, intermittent irrigation was adopted after midseason drying to keep water table at $0-3 \mathrm{~cm}$ below soil surface so that the soil was saturated without obvious standing water. In the FR plots, there was no more irrigation since $15 \mathrm{~d}$ after transplanting, so the soil moisture was mainly below saturation from the shooting stage to harvest. Specific field water conditions are shown in Fig. 2. A local popular hybrid rice cv. Fengyuanyou 299 was used in this study. Seedlings were raised in the seedbed with the sowing date being 20 June, and transplanted on 19 July at a hill spacing yield gap between saturated soil culture and conventional irrigation (FDF and FR). Photosynthesis is an important physiological process that is sensitive to water deficit (Pieters and Nùñez 2008, Akram et al. 2013, Perdomo et al. 2015, 2017). Photosynthetic capacity, especially during the reproductive stage, is crucial for grain formation (Akram et al. 2013, Ambavaram et al. 2014). In rice, more than $60 \%$ of the carbon content of grains originates from $\mathrm{CO}_{2}$ assimilation during the grain-filling stage, and flag leaves are the primary contributors to the accumulation of dry matter in grains (Yoshida 1981). The objective of the research is to investigate the responses of photosynthetic gas exchange, chlorophyll (Chl) fluorescence, grain yield, and water-use efficiency of rice to different water management strategies under the climatic conditions of southern China. The results can give insight into understanding of photosynthetic physiology underlying water-saving cultivation of rice.

of 0.20 by $0.20 \mathrm{~m}$ with two seedlings per hill. The heading date $(50 \%$ of the panicles fully emerged from the boot) started from 6 September. After heading and flowering, the grains entered the filling stage. Plants were harvested by hand on 10 October. The fertilizers applied were urea for $\mathrm{N}$, calcium superphosphate for $\mathrm{P}$, and potassium chloride for $\mathrm{K}$, at the rates of $101 \mathrm{~kg}(\mathrm{~N}) \mathrm{ha}^{-1}, 20 \mathrm{~kg}(\mathrm{P}) \mathrm{ha}^{-1}$, and 110 $\operatorname{kg}(\mathrm{K}) \mathrm{ha}^{-1}$, respectively. Urea was applied with three splits, with $50 \%$ as a basal fertilizer, $33.3 \%$ as tillering fertilizer, and $16.7 \%$ as panicle fertilizer. The calcium superphosphate and potassium chloride were applied as basal fertilizers. Weeds, pests, and diseases were controlled as required to avoid a yield loss.

Gas exchange: Photosynthetic gas-exchange parameters were measured on fully expanded flag leaves using a portable photosynthesis measuring system (LI-6400, Li-Cor Inc., Lincoln, NE, USA) during 09:30-11:30 h on cloudless days, 6 September during the heading stage, and 24 September during the filling stage. PPFD of $1,500 \mu \mathrm{mol}$ $\mathrm{m}^{-2} \mathrm{~s}^{-1}$ was provided by light-emitting diode (model 6400 $02 B$ Red-Blue, $\mathrm{Li}$-Cor Inc.). Temperature of a leaf chamber was controlled for all measurements at $30^{\circ} \mathrm{C} . \mathrm{CO}_{2}$ concentration was provided and controlled by the $\mathrm{CO}_{2}$ injector system at $400 \mu \mathrm{mol} \mathrm{mol}{ }^{-1}$. Net photosynthetic rate $\left(P_{\mathrm{N}}\right)$, stomatal conductance $\left(g_{\mathrm{s}}\right)$, transpiration rate $(E)$, intercellular $\mathrm{CO}_{2}$ concentration $\left(C_{\mathrm{i}}\right)$, and ambient $\mathrm{CO}_{2}$ concentration $\left(C_{\mathrm{a}}\right)$ were obtained directly. Stomatal limitation value $\left(\mathrm{L}_{\mathrm{s}}\right)$ was calculated using the following formula: $\mathrm{L}_{\mathrm{s}}=1-C_{\mathrm{i}} / C_{\mathrm{a}}$

Chl fluorescence parameters were measured on fully expanded flag leaves using a Mini-PAM fluorometer (Walz, Germany). Mini-PAM fluorometer uses three different lights to manipulate the photosynthetic apparatus, measuring light to excite fluorescence, saturating pulse 
$\left[3,000 \mu \mathrm{mol}\right.$ (photon) $\left.\mathrm{m}^{-2} \mathrm{~s}^{-1}, 0.8 \mathrm{~s}\right]$ to close all PSII reaction centers to determine maximum fluorescence, and actinic light to induce photosynthesis (electron transport). Minimal fluorescence yield $\left(\mathrm{F}_{0}\right)$ and maximal fluorescence yield $\left(\mathrm{F}_{\mathrm{m}}\right)$ were measured before dawn. Diurnal rapid light curves (RLCs) were recorded at 08:00, 10:00, 12:00, 14:00, 16:00, and 18:00 h on a cloudless day, 24 September, during the filling stage. RLCs were measured using the "light curve" routine at nine levels of actinic light $[0,105,215,340,510,720 ; 1,050 ; 1,420 ;$ and 2,180 $\mu$ mol(photon) $\mathrm{m}^{-2} \mathrm{~s}^{-1}$ in an increasing order. Each actinic light lasted for $10 \mathrm{~s}$. At the end of each actinic light, a saturating pulse was applied to measure instantaneous fluorescence $\left(\mathrm{F}_{\mathrm{t}}\right)$ and maximum fluorescence yield at the corresponding actinic light $\left(\mathrm{F}_{\mathrm{m}}{ }^{\prime}\right)$. The following parameters were calculated: effective quantum yield of PSII photochemistry, $\Phi_{\text {PSII }}=\left(\mathrm{F}_{\mathrm{m}}{ }^{\prime}-\mathrm{F}_{\mathrm{t}}\right) / \mathrm{F}_{\mathrm{m}}$, and electron transport rate, $\mathrm{ETR}=0.5 \times \Phi_{\mathrm{PSII}} \times \mathrm{PPFD} \times 0.84$, where 0.5 is a multiplication factor for two quanta of light required for the transport of one electron, and 0.84 is the speciesspecific fraction of incident quanta absorbed by the leaf. To determine the cardinal points of RLCs, the ETR vs. PPFD data were fitted using a double exponential decay
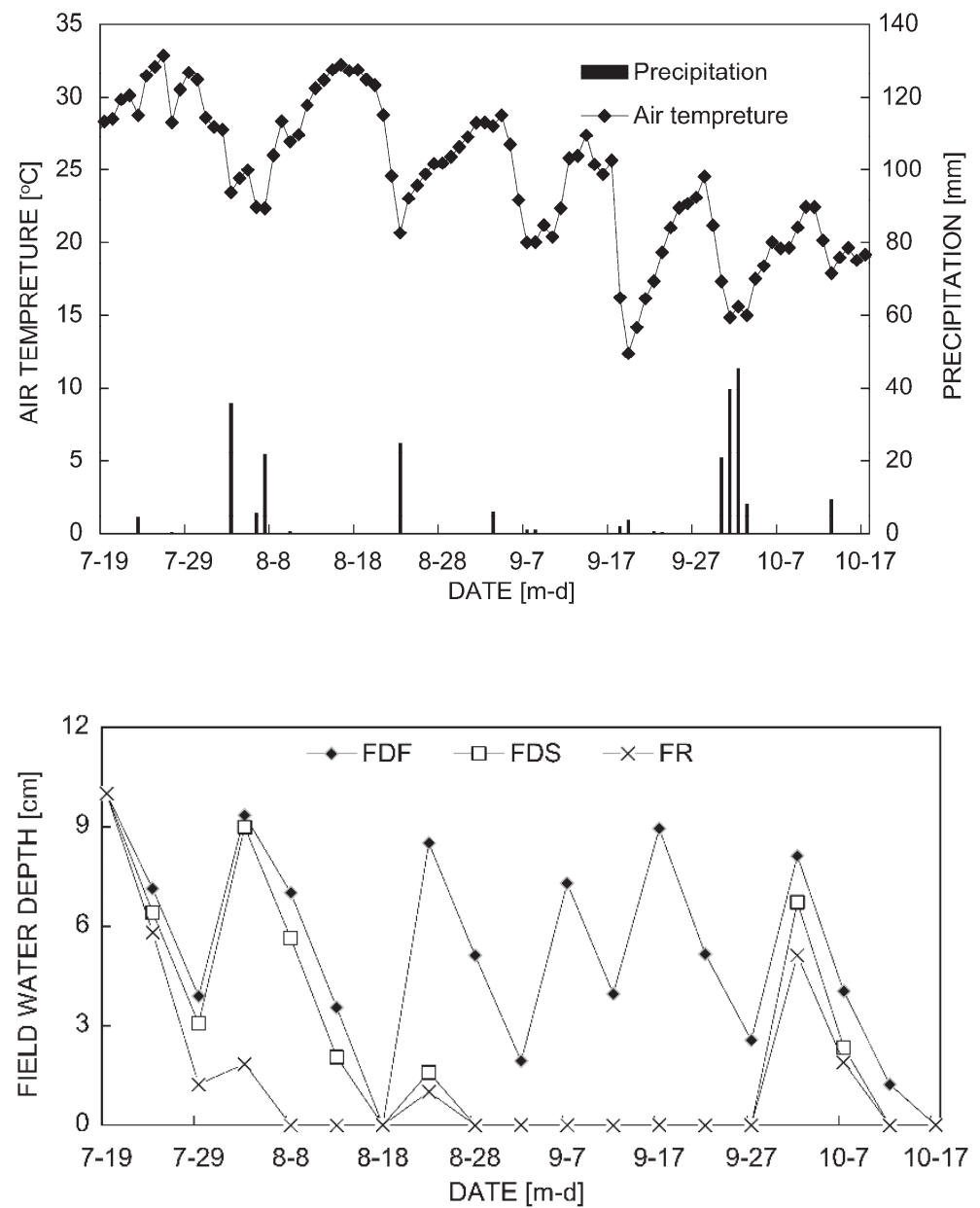

function: $\mathrm{P}=\mathrm{Ps}\left(1-\mathrm{e}^{-(\beta \mathrm{E} / \mathrm{Ps})}\right)$. Light-saturated ETR $\left(\mathrm{ETR}_{\max }\right)$ and saturation irradiance $\left(\mathrm{E}_{\mathrm{m}}\right)$ were estimated using the following equations: $\quad \operatorname{ETR}_{\max }=\operatorname{Ps}[\alpha /(\alpha+\beta)][\beta /(\alpha+\beta)]^{\beta / \alpha}$ and $E_{m}=$ Ps $/ \alpha \log _{e}{ }^{(\alpha+\beta) / \beta}$. The definitions of the parameters can be found in Platt et al. (1980) and Ralph and Gademann (2005).

Rice yield: Rice was harvested manually from each plot at maturity stage. Grain samples were oven-dried at $70^{\circ} \mathrm{C}$ and weighed to calculate grain yields assuming the water content of $14 \%$.

Water productivity: A water flow meter was installed in the irrigation pipeline in each plot to monitor the amount of irrigated water. Water productivity (WP) was calculated as grain yield divided by total amount of irrigated water as follows: WP = grain yield/gross irrigation.

Statistical analysis: The data were analyzed statistically with analysis of variance (ANOVA) using Statistical Package for the Social Sciences 16.0 software. The mean values were compared with the Duncan's post-hoc test with $p<0.05$ considered significant.

Fig. 1. Dynamics of daily rainfall and daily average air temperature throughout the experimental period.

Fig. 2. Dynamics of water table throughout the experimental period. FDF, flooding-midseason dryingflooding water regime; FDS, flooding-midseason drying-saturating water regime; FR, flooding-rainfed water regime. 


\section{Results}

Gas exchange: The gas-exchange parameters at the heading and filling stage are listed in Table 1. FDS plants were comparable to FDF plants in $P_{\mathrm{N}}, g_{\mathrm{s}}, E$, and $\mathrm{L}_{\mathrm{s}}$ at the heading stage. FDS resulted in a small decrease in $P_{\mathrm{N}}, g_{\mathrm{s}}$, and $E$, and a small increase in $\mathrm{L}_{\mathrm{s}}$ at the filling stage. In contrast, FR resulted in an obvious decrease in $P_{\mathrm{N}}, g_{\mathrm{s}}$, and $E$ compared to FDF and FDS at both the heading and filling stage. $\mathrm{L}_{\mathrm{s}}$ of FR plants was significantly higher than that of the FDF and FDS plants. The decrease in $P_{\mathrm{N}}$ and $E$ of FR plants was due to the increase in $\mathrm{L}_{\mathrm{s}}$ and the decrease in $g_{\mathrm{s}}$. Stomata plays a dominant role in the response to leaf water vapor emission loss and carbon dioxide assimilation. The stomatal factor-limited $P_{\mathrm{N}}$ was associated with decreased $g_{\mathrm{s}}$. The FDS plants, however, were not obviously limited by stomata, leading to comparable $P_{\mathrm{N}}$ between FDS and FDF.
Chl fluorescence: RLCs provide important ecophysiological information for understanding potential photosynthesis capacity of leaves. Diurnal changes of RLCs under different water conditions are presented in Figs. 3 and 4. ETR increased with the increase of actinic light. ETR under various water conditions differed in performance, especially during 10:00-16:00 h when air temperature was relatively high and sunlight relatively strong. Diurnal variation curve of ETR under FDF treatment reached the highest values around 12:00 h, while ETR under FDS and FR reached the highest values around 10:00 h. The order of ETR under different treatments was as follows: FDF $>$ FDS $>$ FR.

Table 1. Net photosynthetic rate $\left(P_{\mathrm{N}}\right)$, stomatal conductance $\left(g_{\mathrm{s}}\right)$, and stomatal limitation value $\left(\mathrm{L}_{\mathrm{s}}\right)$ under different water conditions. [PPFD: $1,500 \mu \mathrm{mol}\left(\right.$ photon) $\mathrm{m}^{-2} \mathrm{~s}^{-1}$ ] $P_{\mathrm{N}}-$ net photosynthetic rate; $E$ - transpiration rate; $g_{\mathrm{s}}-$ stomatal conductance; $\mathrm{L}_{\mathrm{s}}-$ stomatal limitation value. FDF - flooding-midseason drying-flooding water regime; FDS - flooding-midseason drying-saturating water regime; FR - flooding-rain-fed water regime. Data within the same column and same stage followed by different letters are significantly different at $p<0.05$ (mean $\pm \mathrm{SE}, n=3$ ).

\begin{tabular}{llllll}
\hline Stage & Treatment & $P_{\mathrm{N}}\left[\mu \mathrm{mol}\left(\mathrm{CO}_{2}\right) \mathrm{m}^{-2} \mathrm{~s}^{-1}\right]$ & $g_{\mathrm{s}}\left[\mathrm{mol}\left(\mathrm{H}_{2} \mathrm{O}\right) \mathrm{m}^{-2} \mathrm{~s}^{-1}\right]$ & $E\left[\mathrm{mmol}\left(\mathrm{H}_{2} \mathrm{O}\right) \mathrm{m}^{-2} \mathrm{~s}^{-1}\right]$ & $\mathrm{Ls}_{\mathrm{s}}$ \\
\hline Heading & FDF & $20.9 \pm 0.5^{\mathrm{a}}$ & $0.89 \pm 0.03^{\mathrm{a}}$ & $5.5 \pm 0.1^{\mathrm{a}}$ & $0.14 \pm 0.00^{\mathrm{b}}$ \\
& FDS & $20.2 \pm 0.5^{\mathrm{a}}$ & $0.84 \pm 0.02^{\mathrm{a}}$ & $5.5 \pm 0.1^{\mathrm{a}}$ & $0.14 \pm 0.01^{\mathrm{b}}$ \\
& FR & $16.7 \pm 0.4^{\mathrm{b}}$ & $0.47 \pm 0.05^{\mathrm{b}}$ & $4.2 \pm 0.2^{\mathrm{b}}$ & $0.19 \pm 0.01^{\mathrm{a}}$ \\
Filling & FDF & $20.7 \pm 0.5^{\mathrm{a}}$ & $0.93 \pm 0.04^{\mathrm{a}}$ & $8.6 \pm 0.3^{\mathrm{a}}$ & $0.14 \pm 0.01^{\mathrm{b}}$ \\
& FDS & $19.1 \pm 0.3^{\mathrm{b}}$ & $0.75 \pm 0.02^{\mathrm{b}}$ & $7.8 \pm 0.3^{\mathrm{a}}$ & $0.16 \pm 0.01^{\mathrm{b}}$ \\
& FR & $16.6 \pm 0.6^{\mathrm{c}}$ & $0.59 \pm 0.06^{\mathrm{c}}$ & $5.2 \pm 0.3^{\mathrm{b}}$ & $0.19 \pm 0.01^{\mathrm{a}}$ \\
\hline
\end{tabular}

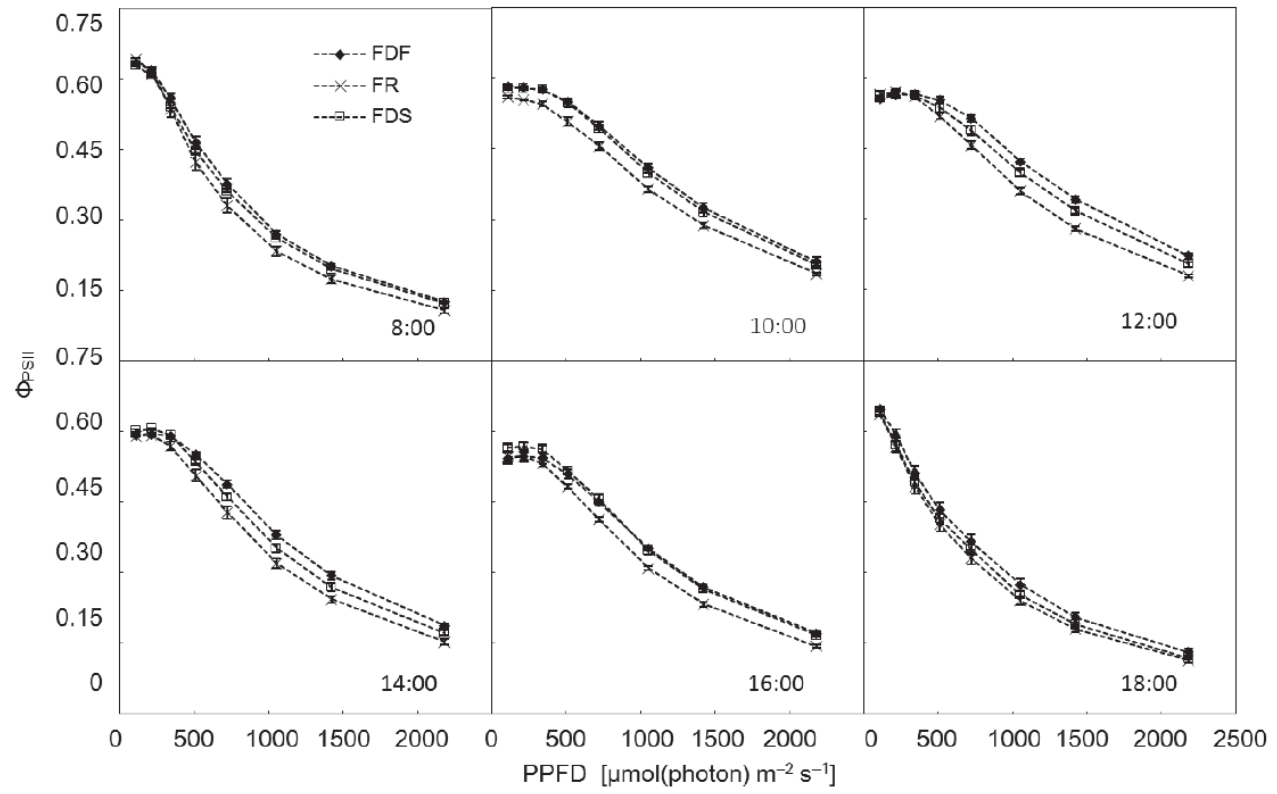

Fig. 3. Diurnal changes of rapid light curves under different water conditions at the filling stage (mean \pm SE, $n=3$ ). $\Phi$ PSII - effective quantum yield of PSII photochemistry; FDF - flooding-midseason drying-flooding water regime; FDS - flooding-midseason drying -saturating water regime; FR - flooding-rain-fed water regime. 


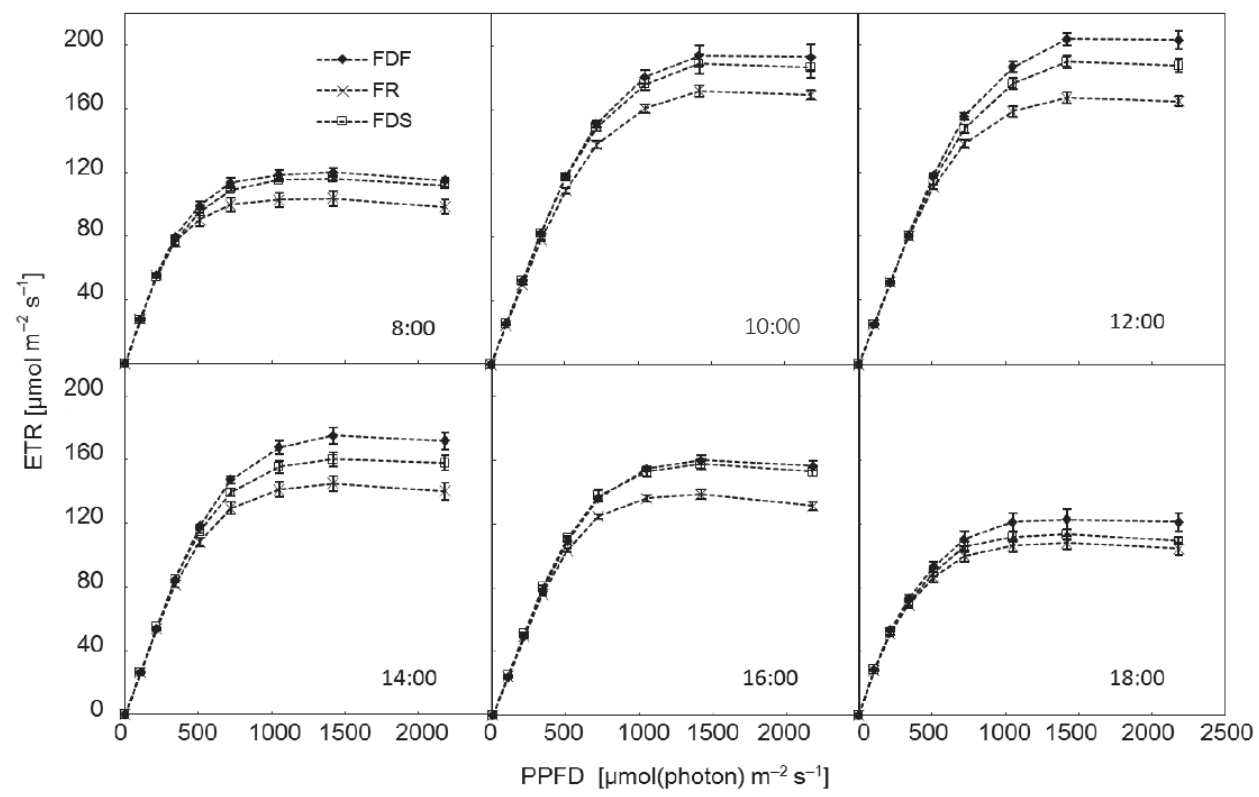

Fig. 4. Diurnal changes of rapid light curves under different water conditions at the filling stage (mean \pm SE, $n=3$ ). ETR - electron transport rate; FDF - flooding-midseason drying-flooding water regime; FDS - flooding-midseason drying-saturating water regime; FR - flooding-rain-fed water regime.

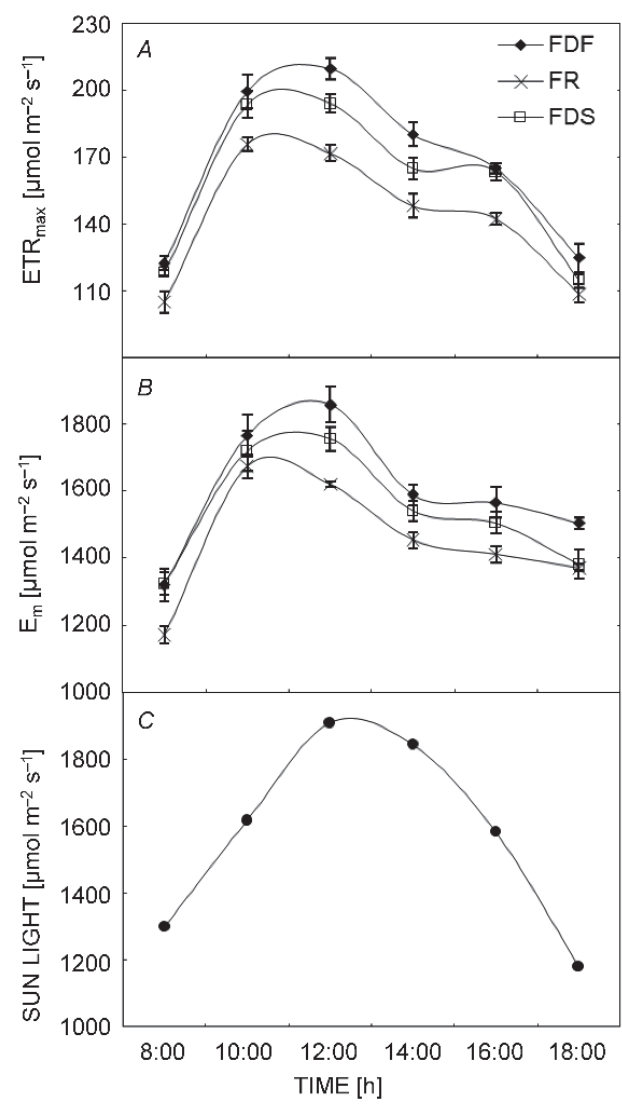

Fig. 5. Diurnal changes of $\mathrm{ETR}_{\max }(A), \mathrm{E}_{\mathrm{m}}(B)$, and sun light $(C)$ under different water conditions at the filling stage (mean $\pm \mathrm{SE}$, $n=3)$. $\mathrm{E}_{\mathrm{m}}$ - saturation irradiance; $\mathrm{ETR}_{\max }-$ light-saturated electron transport rate; FDF - flooding-midseason drying-flooding water regime; FDS - flooding-midseason drying-saturating water regime; FR-flooding-rain-fed water regime.
$\mathrm{ETR}_{\max }$ and $\mathrm{E}_{\mathrm{m}}$ curves under different water conditions are presented in Fig. 5. Compared to FDF, FR decreased $\mathrm{ETR}_{\max }$ and saturating irradiance obviously. However, FDS showed a lesser decrease. The decreases in saturating irradiance would reduce light-utilization efficiency, especially on cloudless days. ETR max $_{\max }$ curve of FDF tended to have a single peak and peak at about $12: 00 \mathrm{~h}$, while ETR $_{\text {max }}$ curves of FR and FDS tended to have double peaks and get the first peak before noon. In addition, the differences of $E_{m}$ curves under different treatments were similar with that of ETR max $_{\text {ax }}$ curves. During the measuring day, the sunlight obviously exceeded the $E_{m}$ at 14:00 $h$ (Fig. 5B,C). The orders of ETR $\mathrm{Emax}_{\max }$ and $\mathrm{E}_{\mathrm{m}}$ under different treatments were consistent (FDF $>$ FDS $>$ FR). The results indicate that photosynthesis of FR and FDS plants tended to suffer midday depression.

Rice yield and water productivity: Rice yield, irrigation amount, and water productivity (WP) are listed in Table 2. Rice yields under FDF and FDS were comparable, and they were significantly higher than that under FR. Compared to FDF, FDS resulted in $2.8 \%$ of a yield decline. In contrast, FR decreased rice yield by $22 \%$. Compared to FDF, FDS and FR saved 17.2 and $53.5 \%$ of irrigation water, respectively. Correspondingly, WP was enhanced by 17.2 and $67.5 \%$ under FDS and FR, respectively. FDS not only maintained the grain yield, but also saved irrigation water. With a combination of rainfall $(234 \mathrm{~mm})$ and irrigation, the WP were $0.66,0.73$, and $0.84 \mathrm{~kg} \mathrm{~m}^{-3}$ for FDF, FDS, and FR, respectively. 


\section{Discussion}

Rice can survive under a range of water conditions. Its photosynthesis, however, is affected if the soil water content is insufficient. As this study showed, $P_{\mathrm{N}}, g_{\mathrm{s}}, E$, and $\mathrm{L}_{\mathrm{s}}$ of rice plants were influenced by field water conditions. Photosynthesis is the primary drive for rice production, which is closely correlated with stomatal conductance (Ohsumi et al. 2008, Pieters and Nùñez 2008, Ambavaram et al. 2014, Stuerz et al. 2014). In the present study, low $P_{\mathrm{N}}$ and $E$ under non-flooding conditions were caused by high $\mathrm{L}_{\mathrm{s}}$ and low $g_{\mathrm{s}}$, which prevented losing too much water and increased water-use efficiency, showing a strong selfregulatory and adaptive capacity. Nguyen et al. (2009) concluded that $g_{\mathrm{s}}$ under saturated soil conditions was reduced by $13-27 \%$ compared to that under conventional flooding system, whereas other physiological parameters were not affected much by water treatments, particularly when the water table was maintained at around $10 \mathrm{~cm}$ below soil surface. In the present study, plants under FDS showed little differences compared to plants under FDF in $P_{\mathrm{N}}, g_{\mathrm{s}}, E$, and $\mathrm{L}_{\mathrm{s}}$, indicating that it was feasible to reduce irrigation by switching from FDF to FDS.

RLCs can provide detailed information on saturation characteristics of electron transport as well as overall photosynthetic performance of a plant (Ralph and Gademann 2005). Drought could decrease effective quantum yield of PSII photochemistry $\left(\Phi_{\text {PSII }}\right)$ and is main regulatory mechanisms in rice (Pieters and El Souki 2005). Similarly, in the present study, diurnal courses of ETR corresponding diurnal courses of $\Phi_{\mathrm{PSII}}$ varied greatly under different water conditions (Figs. 3, 4). Diurnal changes of RLCs occurred mainly due to diurnal changes in the microclimate, i.e. radiation, temperature, relative humidity, etc. Photosynthesis cannot proceed without photons, but not all the absorbed photons can be utilized in the process of photosynthesis (Kumagai et al. 2009). Excessive radiation loads in canopy leaves can produce reactive oxygen species, which can damage the photosynthetic apparatus, particularly PSII, resulting in photoinhibition due to an imbalance in the photosynthetic redox signaling pathways and the inhibition of PSII repair (Foyer and Noctor 1999, Gururani et al. 2015). Drought-induced inhibition of

Table 2. Rice grain yield, irrigation amount, and water productivity (WP) under different treatments. FDF - floodingmidseason drying-flooding water regime; FDS - floodingmidseason drying-saturating water regime; FR - flooding-rainfed water regime. Data within the same column followed by different letters are significantly different at $p<0.05$ (mean $\pm \mathrm{SE}$, $n=3)$.

\begin{tabular}{llll}
\hline Treatment & Yield $\left[\mathrm{kg} \mathrm{ha}^{-1}\right]$ & Irrigation $\left[\mathrm{m}^{3} \mathrm{ha}^{-1}\right]$ & WP $\left[\mathrm{kg} \mathrm{m}^{-3}\right]$ \\
\hline FDF & $5,647 \pm 161^{\mathrm{a}}$ & $6,221 \pm 169^{\mathrm{a}}$ & $0.91 \pm 0.05^{\mathrm{c}}$ \\
FDS & $5,490 \pm 188^{\mathrm{a}}$ & $5,149 \pm 87^{\mathrm{b}}$ & $1.07 \pm 0.04^{\mathrm{b}}$ \\
FR & $4,403 \pm 110^{\mathrm{b}}$ & $2,890 \pm 70^{\mathrm{c}}$ & $1.52 \pm 0.04^{\mathrm{a}}$ \\
\hline
\end{tabular}

photosynthesis appeared gradually with growing radiation (Fig. 5). High temperature and low relative humidity could aggravate photodepression, especially under non-flooding conditions (Perdomo et al. 2015, 2017). Non-flooded rice fields had higher sensible heat flux and lower latent heat flux compared to flooded fields, indicating that a large proportion of available net radiation was used for sensible heat transfer or for the warming of the surrounding air (Alberto et al. 2009, 2011), which resulted in a higher canopy temperature and lower relative humidity (Yan et al. 2012, Stuerz et al. 2014). In the present study, compared to FDF, the FR and FDS plants were more likely subjects to midday photodepression (Fig. 5), indicating that photosynthetic performance at midday may allow more precise estimate of water stress.

With rapid population growth and increasing water scarcity, it is critically important to sustain high grain yields through improved water productivity. In paddy fields, irrigation without standing water would lead to lesser water loss from evaporation, percolation, seepage, and surface runoff (Bouman et al. 2007, Alberto et al. 2011). In the present study, the highest water productivity (WP) was observed in FR treatment, which showed the lowest grain yield. High yield production with relatively high WP was observed in FDS treatment, with an increase of $17.2 \%$ in WP and a reduction of only $2.8 \%$ in yield in comparison with FDF treatment (Table 2). The result was consistent with previous studies (e.g., Bouman and Tuong 2001, Tabbal et al. 2002, Zain et al. 2014). It indicates that FDS could provide sufficient moisture for a high rice yield. Such association of high (or moderate) WP values with high (or moderate) yield has an important implication for water-saving irrigation management. Also, saturated soil culture increased grain yields in some studies (e.g., Pan et al. 2009, He 2010, Escasinas and Zamora 2011, He et al. 2014). The dispute could be attributed to differences in climates, soil properties, and varieties (Belder et al. 2004, Nguyen et al. 2009, Matsuo et al. 2010, Akram et al. 2013, Chu et al. 2014, Fong et al. 2016). It indicates that FDS system could guarantee yield, as long as minimum soil moisture was controlled reasonably according to local climates, soil properties, and varieties.

Continuous flooding was widely adopted before 1980s and gradually replaced by midseason drying (FDF). To cope with water scarcity, people have adopted partly nonflooded management strategies, such as alternate wetting and drying culture and FDS described in the present study. With efficient alternate wetting and drying irrigation, soil was dried out to a reasonable threshold between irrigation events, which could greatly reduce water input without reducing the rice yield (Thakur et al. 2014, Lampayan et al. 2015, Kumar et al. 2017). In contrast, no standing water existed in saturated soil culture, which would reduce more water loss. In practice, irrigation is adopted not only for 
crop growth but also as a management tool during rice cultivation. Soil flooding provides favorable conditions for soil pounding, seedling transplanting, and weed control (Nguyen et al. 2009). There was usually abundant rainfall during early-middle periods of single-season rice and lateseason rice, which made it easy to implement soil flooding during early-middle periods. Therefore, FDS in the present study also conformed to integrative field management and precipitation distribution.

Conclusion: In this study, RF significantly inhibited rice photosynthesis and yield, as compared to FDF. However,

\section{References}

Akram H.M., Ali A., Sattar A. et al.: Impact of water deficit stress on various physiological and agronomic traits of three basmati rice (Oryza sativa L.) cultivars. - J. Anim. Plant Sci. 23: 14151423, 2013.

Alberto M.C.R, Wassmann R., Hirano T. et al.: $\mathrm{CO}_{2} /$ heat fluxes in rice fields: Comparative assessment of flooded and nonflooded fields in the Philippines. - Agr. Forest Meteorol. 149: 1737-1750, 2009.

Alberto M.C.R., Wassmann R., Hirano T. et al.: Comparisons of energy balance and evapotranspiration between flooded and aerobic rice fields in the Philippines. - Agr. Water Manage. 98: 1417-1430, 2011.

Ambavaram M.M.R., Basu S., Krishnan A. et al.: Coordinated regulation of photosynthesis in rice increases yield and tolerance to environmental stress. - Nat. Commun. 5: 5302, 2014.

Barker R., Tuong T.P., Li Y. et al.: Growing more rice with less water: Research findings from a study in China. - Paddy Water Environ. 2: 185-185, 2004.

Belder P., Bouman B.A.M., Cabangon R. et al.: Effect of watersaving irrigation on rice yield and water use in typical lowland conditions in Asia. - Agr. Water Manage. 65: 193-210, 2004.

Bouman B.A.M., Lampayan R.M., Tuong T.P.: Water Management in Irrigated Rice: Coping with Water Scarcity. Pp. 54. Int. Rice Res. Inst., Los Baños 2007.

Bouman B.A.M., Toung T.P.: Field water management to save water and increase its productivity in irrigated lowland rice. Agr. Water Manage. 49: 11-30, 2001.

Chu G., Chen T., Wang Z. et al.: Morphological and physiological traits of roots and their relationships with water productivity in water-saving and drought-resistant rice. - Field Crop. Res. 162: 108-119, 2014.

Elliott J., Deryng D., Müller C. et al.: Constraints and potentials of future irrigation water availability on agricultural production under climate change. - P. Natl. Acad. Sci. USA 111: 32393244, 2013.

Escasinas R.O., Zamora O.B.: Agronomic response of lowland rice PSB Rc 18 (Oryza sativa L.) to different water, spacing and nutrient management. - Philipp. J. Crop Sci. 36: 37-46, 2011.

FAO (Food and Agriculture Organization of the United Nations): The Database of FAOSTAT. 2014. Available online: http://www.fao.org/faostat/en/\#data/QC/visualize, accessed on May 19, 2017.

Fong J.D.M., Masunaga T., Sato K.: Assessment of the influence of water management on yield component and morphological behavior of rice at post-heading stage. - Paddy Water Environ.
FDS substantially alleviated these reductions, and their values were not significantly different from those of FDF. Therefore, we concluded that FDS (water table was $0-3 \mathrm{~cm}$ below soil surface after midseason drying) could be considered as an effective irrigation regime to increase water productivity without obvious adverse effects on photosynthetic capacity and grain yield in rice cultivation. With increasing water scarcity, lower water input in rice cultivation is inevitable. This study would be instructive for determining water-saving cultivation method and exploring relations between water management and photosynthetic physiology.

14: 211-220, 2016

Foyer C.H., Noctor G.: Leaves in the dark see the light. - Science 284: 599-601, 1999.

Gururani M.A., Venkatesh J., Tran L.S.P.: Regulation of photosynthesis during abiotic stress-induced photoinhibition. - Mol. Plant 8: 1304-1320, 2015.

He C.L.: Effects of furrow irrigation on the growth, production, and water use efficiency of direct sowing rice. - Sci. World J. 10: 1483-1497, 2010.

He H., Yang R., Jia B. et al.: Rice photosynthetic productivity and PSII photochemistry under nonflooded irrigation. - Sci. Word J. 2014: 839658, 2014.

Khush G.S.: What it will take to feed 5.0 billion rice consumers in 2030. - Plant Mol. Biol. 59: 1-6, 2005.

Kumagai E., Araki T., Ueno O.: Effect of nitrogen-deficiency on midday photoinhibition in flag leaves of different rice (Oryza sativa L.) cultivars. - Photosynthetica 47: 241-246, 2009.

Kumar A., Nayak A.K., Pani D.R. et al.: Physiological and morphological responses of four different rice cultivars to soil water potential based deficit irrigation management strategies. - Field Crop. Res. 205: 78-94, 2017.

Lampayan R.M., Rejesus R.M., Singleton G.R. et al.: Adoption and economics of alternate wetting and drying water management for irrigated lowland rice. - Field Crop. Res. 170: 95-108, 2015.

Lal R., Delgado J.A., Gulliford J. et al.: Adapting agriculture to drought and extreme events. - J. Soil Water Conserv. 67: 162A-167A, 2012.

Matsuo N., Ozawa K., Mochizuki T.: Physiological and morphological traits related to water use by three rice (Oryza sativa L.) genotypes grown under aerobic rice systems. - Plant Soil 335: 349-361, 2010.

Nguyen H.T., Fischer K.S., Fukai S.: Physiological responses to various water saving systems in rice. - Field Crop. Res. 112: 189-198, 2009.

Ohsumi A., Hamasaki A., Nakagawa H. et al.: Response of leaf photosynthesis to vapor pressure difference in rice (Oryza sativa L.) varieties in relation to stomatal and leaf internal conductance. - Plant Prod. Sci. 11: 184-191, 2008.

Pan S.G., Cao C.G., Cai M.L. et al.: Effects of irrigation regime and nitrogen management on grain yield, quality and water productivity in rice.- J. Food Agric. Environ. 7: 559-564, 2009.

Perdomo J.A., Conesa M.A, Medrano H. et al.: Effects of longterm individual and combined water and temperature stress on the growth of rice, wheat and maize: relationship with morpho- 
logical and physiological acclimation. - Physiol. Plantarum 155: 149-165, 2015.

Perdomo J.A., Capo-Bauca S., Carmo-Silva E. et al.: Rubisco and rubisco activase play an important role in the biochemical limitations of photosynthesis in rice, wheat, and maize under high temperature and water deficit. - Front. Plant Sci. 8: 490, 2017.

Pieters A.J., El Souki S.: Effects of drought during grain filling on PSII activity in rice. - J. Plant Physiol. 162: 903-911, 2005.

Pieters A.J., Nùñez M.: Photosynthesis, water use efficiency, and $\delta^{13} \mathrm{C}$ in two rice genotypes with contrasting response to water deficit. - Photosynthetica 46: 574-580, 2008.

Platt T., Gallegos C.L., Harrison W.G.: Photoinhibition of photosynthesis in natural assemblages of marine phytoplankton. - J. Mar. Res. 38: 687-701, 1980.

Ralph P.J., Gademann R.: Rapid light curves: a powerful tool to assess photosynthetic activity. - Aquat. Bot. 82: 222-237, 2005.

Stuerz S., Sow A., Muller B. et al.: Canopy microclimate and gas-exchange in response to irrigation system in lowland rice in the Sahel. - Field Crop. Res. 163: 64-73, 2014.

Tabbal D.F., Bouman B.A.M., Bhuiyan S.I. et al:: On-farm strategies for reducing water input in irrigated rice: case studies in the Philippines. - Agr. Water Manage. 56: 93-112, 2002.
Thakur A.K., Mohanty R.K., Patil D.U. et al.: Impact of water management on yield and water productivity with system of rice intensification (SRI) and conventional transplanting system in rice. - Paddy Water Environ. 12: 413-424, 2014.

Wei X., Holman I., Lin E. et al.: Climate change, water availability and future cereal production in China. - Agr. Ecosyst. Environ. 135: 58-69, 2010.

Yan C., Chen H., Fan T. et al.: Rice flag leaf physiology, organ and canopy temperature in response to water stress. - Plant Prod. Sci. 15: 92-99, 2012.

Yan T., Wang J., Huang J.: Urbanization, agricultural water use, and regional and national crop production in China. - Ecol. Model. 318: 226-235, 2015.

Yoshida S.: Physiological analysis of rice yield. - In: Yoshida S. (ed.): Fundamentals of Rice Crop Science. Pp. 231-251. Int. Rice Res. Inst., Los Baños 1981.

Zain N.A.M., Ismail M.R., Puteh A. et al.: Impact of cyclic water stress on growth, physiological responses and yield of rice (Oryza sativa L.) grown in tropical environment. - Cienc. Rural. 44: 2136-2141, 2014.

Zhou Q., Ju C.X., Wang Z.Q. et al.: Grain yield and water use efficiency of super rice under soil water deficit and alternate wetting and drying irrigation. - J. Integr. Agr. 16: 1028-1043, 2017. 